\title{
Does a Standardized Distance Cut-off Accurately Predict the Length of the Rectum? Using MRI to Analyze the Height of the Peritoneal Reflection
}

\author{
Standartlaştırılmış Mesafe Eşiği Rektumun Uzunluğunu Doğru Bir Şekilde \\ Öngörür mü? Peritoneal Refleksiyonun Yüksekliğini Analiz Etmede MRG \\ Kullanımı
}

\author{
(1) Jordan Wlodarczyk1, (1) Genia Taitano², (1) Nicholas Serniak1, (1) Jason Murri1, (1) Marjun P. Duldulao1, \\ (1) Kyle G. Cologne ${ }^{1}$, (1) Sang Won Lee1 \\ ${ }^{1}$ Keck Hospital of USC, Clinic of Colorectal Surgery, Los Angeles, USA \\ ${ }^{2}$ Keck Hospital of USC, Clinic of General Surgery, Los Angeles, USA
}

\section{HIIIIII ABSTRACT}

Aim: Standardized distance cut-offs are frequently utilized as a surrogate in determining whether neoadjuvant therapy is needed in treating upper rectal cancer. With patient-to-patient variation in rectal length this method can prove inaccurate. This article establishes the range of natural variation in the height of this structure in patients and if standardized measurement cut-offs are inappropriate in characterizing its location.

Method: Retrospective chart review, from 2015 to 2019, of patients in whom pre-operative rectal cancer staging magnetic resonance imaging was undertaken. Measurement from the anal verge to the anterior peritoneal reflection (APR) and sigmoid take-off (ST) was performed. Differences between genders were compared and distance measurement correlations with height, weight, age, and body mass index were investigated.

Results: Mean overall height of the APR was $11.9 \pm 2.0 \mathrm{~cm}$ from the anal verge. When genders were compared this measurement was $12.3 \pm 2.1 \mathrm{~cm}$ in males and $11.3 \pm 1.5 \mathrm{~cm}$ in females ( $\mathrm{p}=0.003$ ). Overall, the $75^{\text {th }}, 90^{\text {th }}$, and $95^{\text {th }}$ percentile of the height of the APR was $13.2 \mathrm{~cm}, 14.5 \mathrm{~cm}$, and $15.5 \mathrm{~cm}$, respectively. Average height of the rectum at the ST from the anal verge was $19.3 \pm 2.4 \mathrm{~cm}$ and $14.3 \pm 2.1 \mathrm{~cm}$, for men and women, respectively. No anthropometric measurements had a strong correlation with APR height.

Conclusion: Males possess a higher APR and ST over females. This difference resembles the difference between genders in anal canal length. Currently utilized standardized rectal length cut-offs may inappropriately categorize patients as rectal cancer whose tumor may lie above the peritoneal reflection. Keywords: Peritoneal reflection, neoadjuvant chemoradiation, sigmoid take-off, rectum length

\section{|IIIIIII|| ÖZ}

\begin{abstract}
Amaç: Üst rektum kanserinin tedavisinde neoadjuvan tedavinin gerekli olup olmadığının belirlenmesinde standartlaștırılmış mesafe eșikleri sıklıkla kullanılır. Rektal uzunluk hastadan hastaya değişiklik gösterdiğinden bu yöntem yanlış sonuçlar verebilir. Bu makale, hastalarda bu yapının yüksekliğindeki doğal varyasyon aralığını ve konumunu karakterize etmede standart ölçüm eşiklerinin uygun olup olmadığını belirlemektedir.

Yöntem: Ameliyat öncesi rektum kanseri evrelemesi için manyetik rezonans görüntüleme yapılan 2015'ten 2019'a kadar ki hastaların retrospektif tablo incelemesi hazırlanmıştır. Anal sınırdan anterior peritoneal refleksiyona (APR) ve sigmoid take-offa (ST) kadar ölçüm yapıldı. Cinsiyetler arasındaki farklılıklar karşılaştırılmış ve boy, kilo, yaş ve vücut kitle indeksi ile mesafe ölçüm korelasyonları araştırılmıştır.

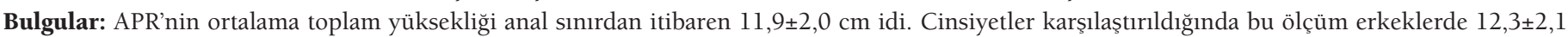

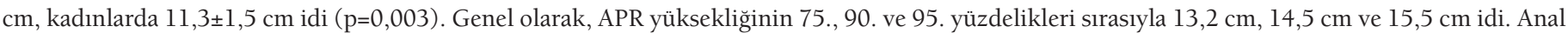

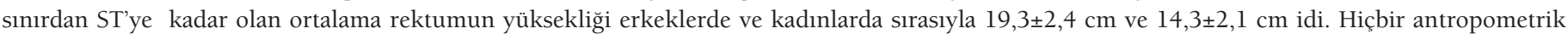
ölçüm APR yüksekliği ile güçlü bir korelasyona sahip değildi.

Sonuç: Erkekler kadınlara göre daha yüksek APR ve ST'ye sahiptir. Bu fark, anal kanal uzunluğundaki cinsiyetler arasındaki farka benzemektedir. Halihazırda kullanılan standartlaştırılmış rektal uzunluk eşikleri, peritoneal refleksiyonun üzerinde yer alan tümörleri yanlışlıkla rektal kanser olarak kategorize edebilir.
\end{abstract}

Anahtar Kelimeler: Peritoneal refleksiyon, neoadjuvan kemoradyoterapi, sigmoid take-off, rektum uzunluğu

Address for Correspondence/Yazışma Adresi: Jordan Wlodarczyk, MD,

Keck Hospital of USC, Clinic of Colorectal Surgery, Los Angeles, USA

E-mail: jordan.wlodarczyk@med.usc.edu ORCID ID: orcid.org/0000-0002-6397-9784

Received/Geliș Tarihi: 26.06.2021 Accepted/Kabul Tarihi: 02.08.2021

${ }^{\oplus}$ Copyright 2021 by Turkish Society of Colon and Rectal Surgery

Turkish Journal of Colorectal Disease published by Galenos Publishing House. 


\section{Introduction}

The delineation between high rectal cancer and distal sigmoid cancer has a profound effect on the clinical treatment course for patients with distal neoplastic colorectal adenocarcinoma. Neoadjuvant chemoradiation therapy before oncologic resection has been established to significantly improve rates of local recurrence for stage II and III rectal cancer. This improvement disappears as tumor distance from the anal verge increases, and thus, patients with distal sigmoid carcinoma are typically recommended to bypass neoadjuvant chemoradiation and typically move straight to oncologic resection. ${ }^{1,2}$ Misclassification of these cancers can lead to unfavorable avoidance or unnecessary administration of potentially life-altering chemoradiation. Chemoradiation has a wide assortment of significant side effects and its effect on quality of life and basic daily bowel function can be evident long after cessation of therapy. ${ }^{3}$ This makes the decision to administer this multimodal therapy challenging.

The decision whether neoadjuvant chemoradiation can provide a significant advantage hinges in part on the ability to accurately localize the disease in relation to its intra-luminal and extra-luminal anatomy, in particular the peritoneal reflection. Differences in the lymphatic distribution between regions of the rectum has been hypothesized to be a reason behind the benefit seen with neoadjuvant chemoradiation. ${ }^{4}$ The clinical advantage of this neoadjuvant therapy disappears around $10-15 \mathrm{~cm}$, suggesting that local and metastatic disease in this region behaves differently. ${ }^{5}$

The American Society of Colon and Rectal Surgeons (ASCRS) Clinical Practice Guidelines for rectal cancer utilizes a distance cut-off to define rectal cancer which is limited to tumors within $15 \mathrm{~cm}$ of the anal verge. ${ }^{6}$ This definition poses inherent limitations, as previous literature has identified variations in the length of the rectum with body habitus and sex. ${ }^{\top}$ Utilizing standardized cut-offs for all patients for the delineation of rectal tumors from distal sigmoid tumors appears to be inappropriate. As the literature has demonstrated, there is a general acceptance in the surgical community that an anatomical landmark, specifically the peritoneal reflection, defines the transition from rectal cancer to distal sigmoid cancer. Thus, utilizing magnetic resonance imaging (MRI) to establish the boundaries of the rectum and the tumor's relation to it, is paramount in delineating rectal from distal sigmoid cancer. ${ }^{8}$ The aim of this study was to establish the average height and variation patterns of the peritoneal reflection, along with other extra-luminal structures, to guide practitioner management for the administration of neoadjuvant chemotherapy. This information can also be used to either guide standardized distance cut-offs for treatment decisions related to neoadjuvant therapy or to exclude this therapy in cases where it would be ineffective.

\section{Materials and Methods}

\section{Study Design}

This manuscript follows STROBE guidelines for a cross sectional observational study. ${ }^{9}$

\section{Setting}

This study was undertaken at an academic, tertiary referral center from January 2016 to November 2019. It evaluated patients with a diagnosis of rectal cancer who underwent pre-operative staging pelvic MRI. Exclusion criteria included patients presenting for rectal cancer recurrence after oncologic resection, previous pelvic surgery obscuring anatomical planes, patients with low quality imaging possessing motion artifact that precluded accurate assessment of tumor location, previous administration of neoadjuvant chemoradiotherapy for rectal cancer, and patients with significant missing data in their electronic medical records.

\section{Primary Outcome}

The primary outcome was the average measurements from the anal verge to the anterior peritoneal reflection (APR) (Figure 1). This was measured on midline sagittal view and identified the anterior fold of the peritoneal reflection in the rectovesical fold or the recto-uterine pouch, using the freehand distance-tracing tool on Synapse (Fugifilm, Valhalla, NY, USA). All measurements were taken by a

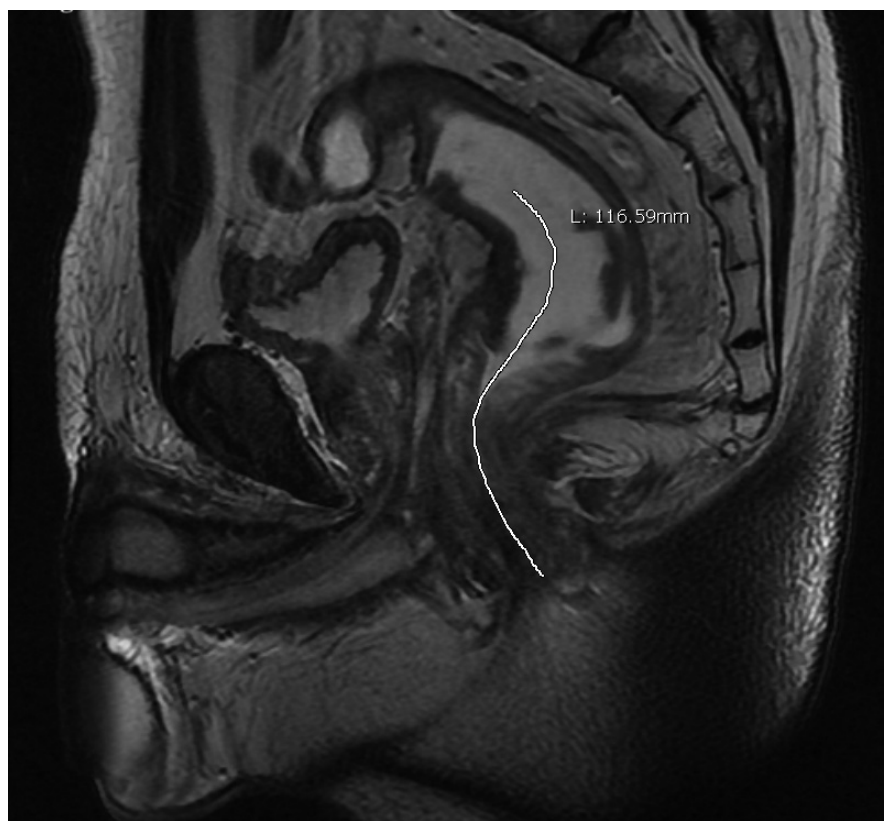

Figure 1. Distance measurements from anal verge to the anterior peritoneal reflection 
single medical professional, trained by a senior professor of clinical radiology and medicine, as is custom for templated reporting at our institution. On pelvic MRI the mid-sagittal $\mathrm{T} 2$ weighted image utilized the freehand distance tracing tool to follow the posterior curve of the rectum from the anal verge to the inferior border of the tumor. ${ }^{10}$ This curvilinear measurement was reported to be a valid method to determine tumor height compared to the gold standard rigid rectoscopy. ${ }^{11}$ This mid-sagittal location allowed for a more accurate representation of luminal distance. The anal verge was defined by its position relative to the anoderm to stratified squamous transition point. This was represented by the transition from hypo-lucent anoderm to hyper-lucent stratified squamous epithelium, which in the radiologic literature has been demonstrated to be a reliable anatomical landmark for the anal verge. ${ }^{10}$ Identical technique was utilized to recreate each measurement from patient to patient to decrease the risk of observation bias. These measurements were taken again two months later with the same technique and were blinded to the previous measurements to confirm their reproducibility.

\section{Secondary Outcome}

Secondary outcomes included height of the APR correlated with height, weight, age, body mass index (BMI), and sex. Other secondary outcomes included the average distance measurement from the pelvic floor to the APR (Figure 2), average distance measurement from the pelvic floor to the sigmoid take-off (ST) (Figure 3), the average distance measurement from the anal verge to the rectal lumen at the sacral prominence (Figure 4), the average distance measurement from the anal verge to the ST (Figure 5). ${ }^{12,13}$ This was done by measuring the APR and posterior

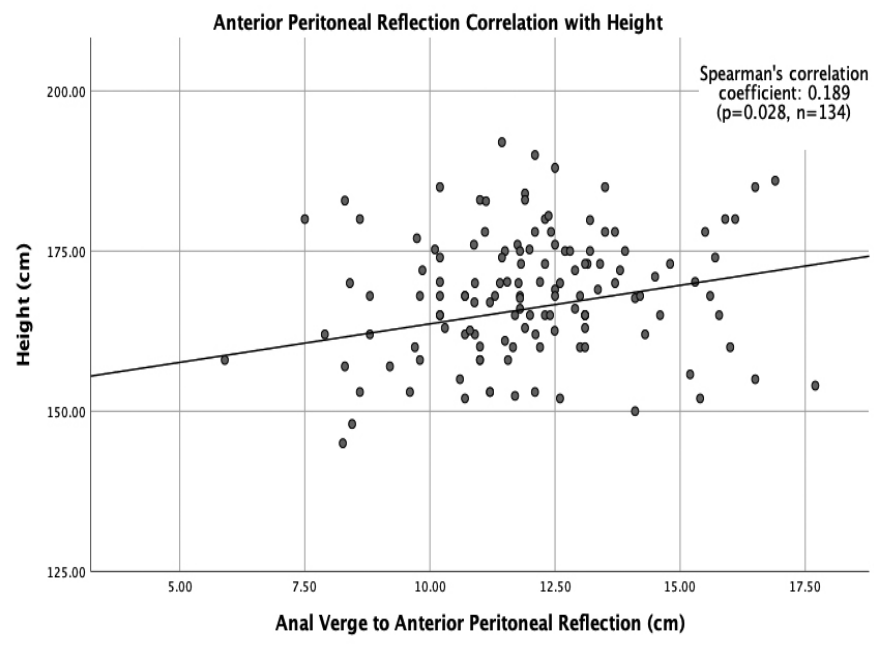

Figure 2. Anterior peritoneal reflection correlation with height peritoneal reflection and identifying a line between the two. The point where that line crossed the center of the rectal lumen was defined as the position of the ST. A further

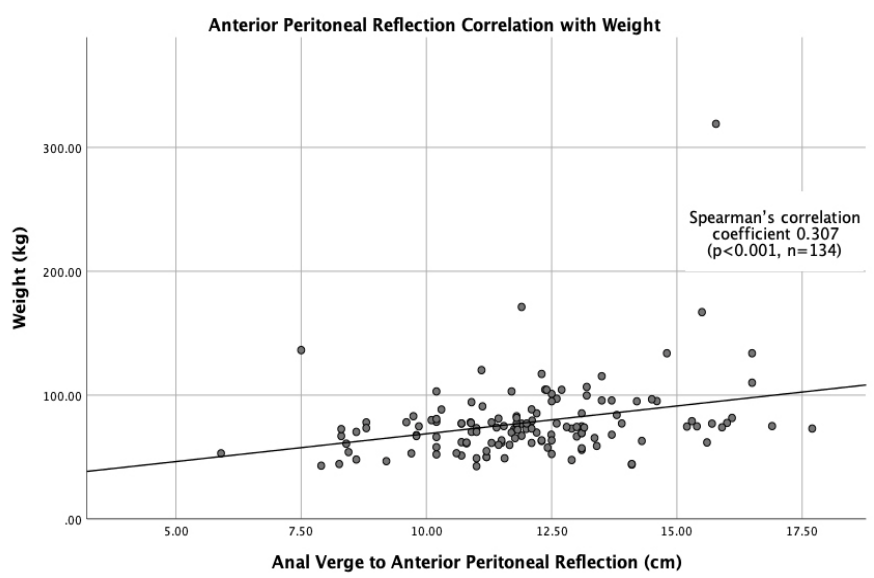

Figure 3. Anterior peritoneal reflection correlation with weight

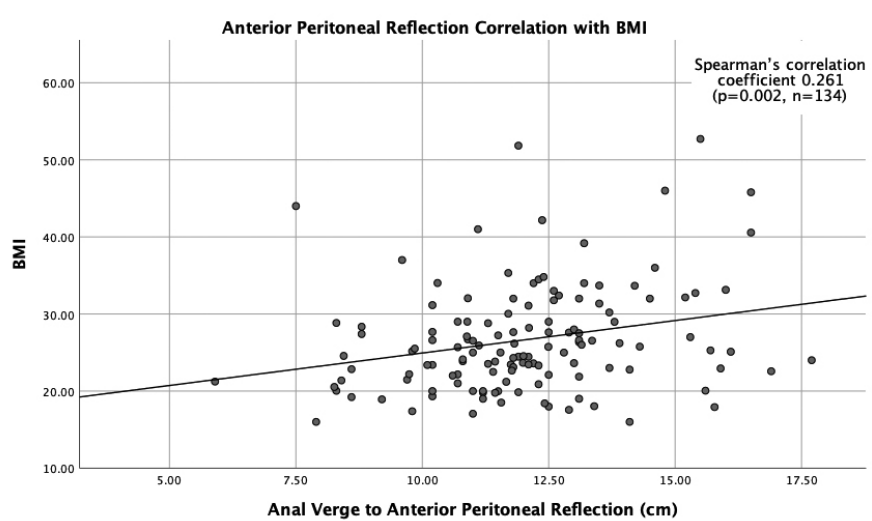

Figure 4. Anterior peritoneal reflection correlation with BMI BMI: Body mass index

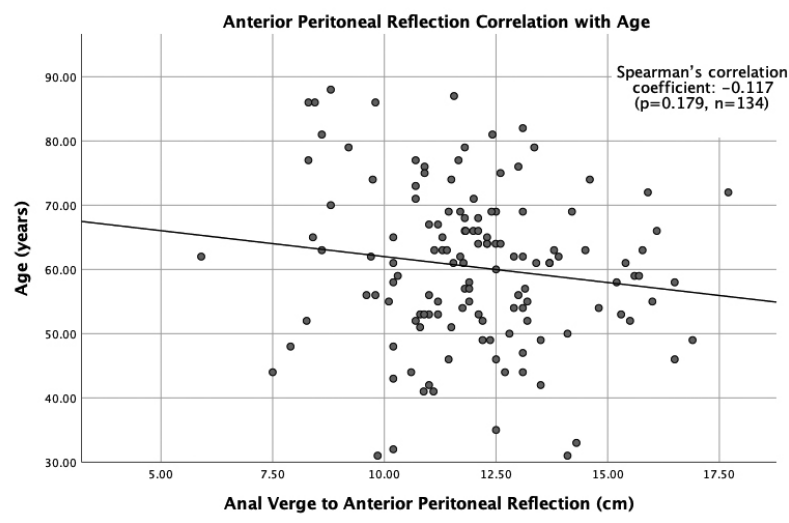

Figure 5. Anterior peritoneal reflection correlation with age 
secondary outcome was the average distance measurement from the anal verge to the prostate and seminal vesicles in males (Figures 6,7 ), and the average anal canal length (Figure 8). Anal canal length was measured on coronal MRI from the inside of the external anal sphincter at the anal verge to the top of the internal anal sphincter and pelvic floor. ${ }^{14}$ The height of the rectum at the sacral prominence was determined by drawing a line from the top of the pubic symphysis to the sacral prominence and using the freehand tracing tool to follow the curve of the rectum along its

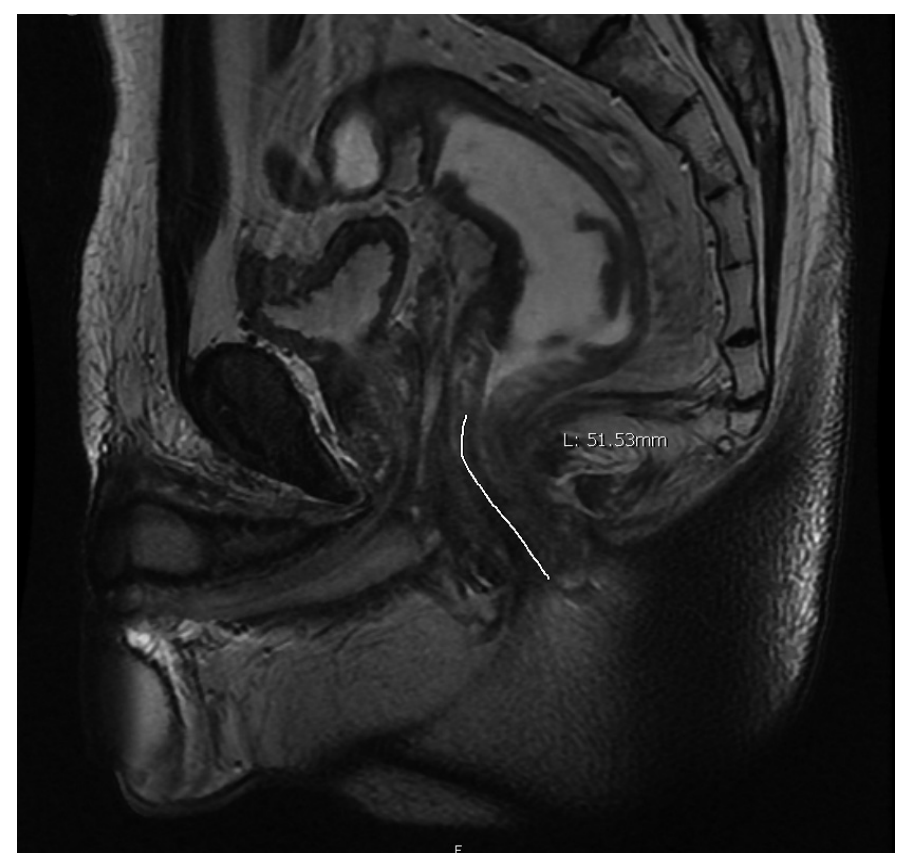

Figure 6. Distance measurements from anal verge to the prostate

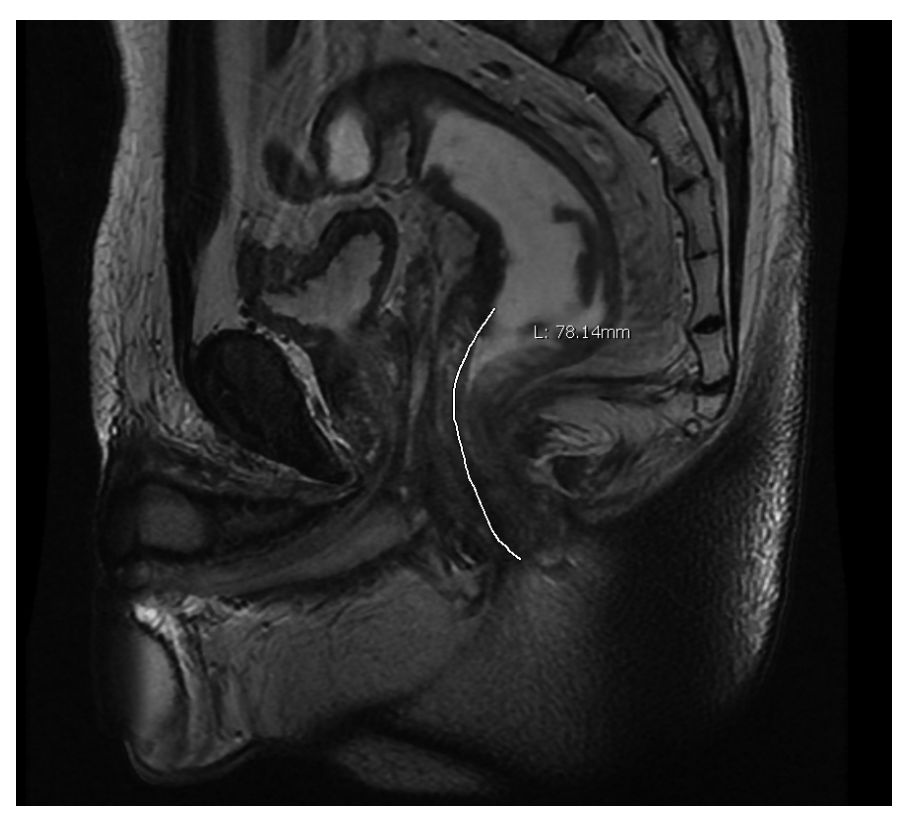

Figure 7. Distance measurements from anal verge to the seminal vesicles posterior wall (Figure 4). The free-hand distance tool was used for all measurements.

\section{Statistical Analysis}

All data and figures were prepared and compiled using the Statistical Package for the Social Sciences, version 26.0 for Macintosh (SPSS Inc, Chicago, IL, USA). Correlations between scale variables were calculated with Spearman correlation coefficients. A Spearman's correlation coefficient of $>0.7,0.69-0.5,0.49-0.3$, and $<0.3$ along with a $\mathrm{p}$ value of $<0.05$ was considered a strong correlation, moderate correlation, weak correlation, and no correlation, respectively. Independent t-tests and Mann-Whitney U tests were used to compare all anatomical and anthropometric measurements between sex. A p value of $<0.05$ demonstrated statistical significance. Intra-class correlation coefficient

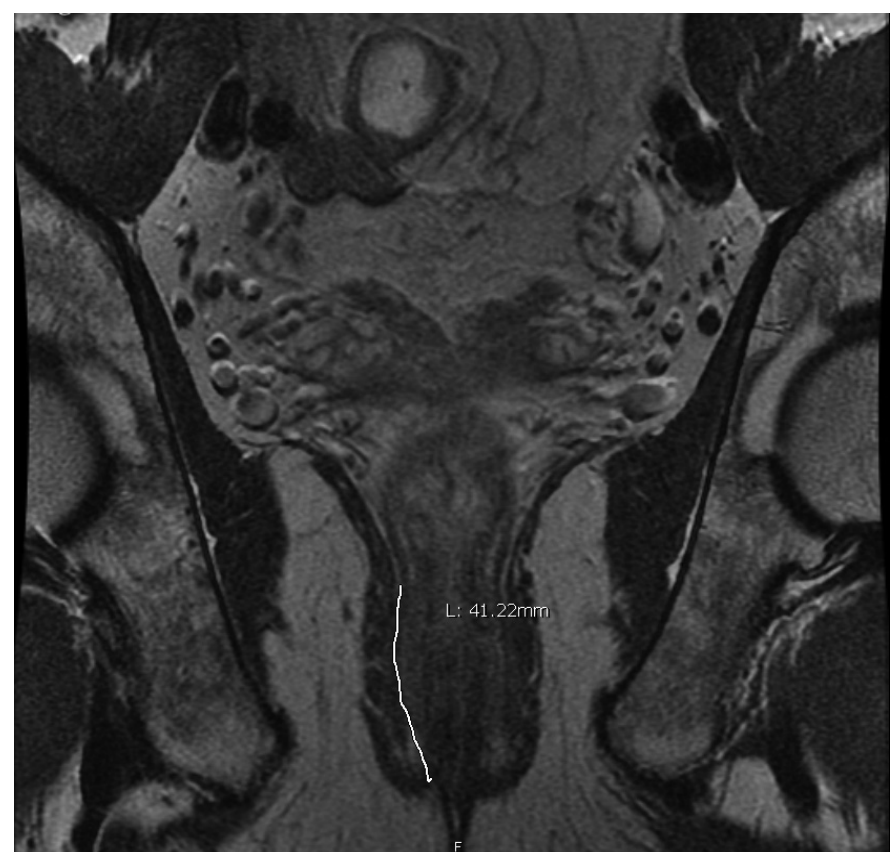

Figure 8. Anal canal distance

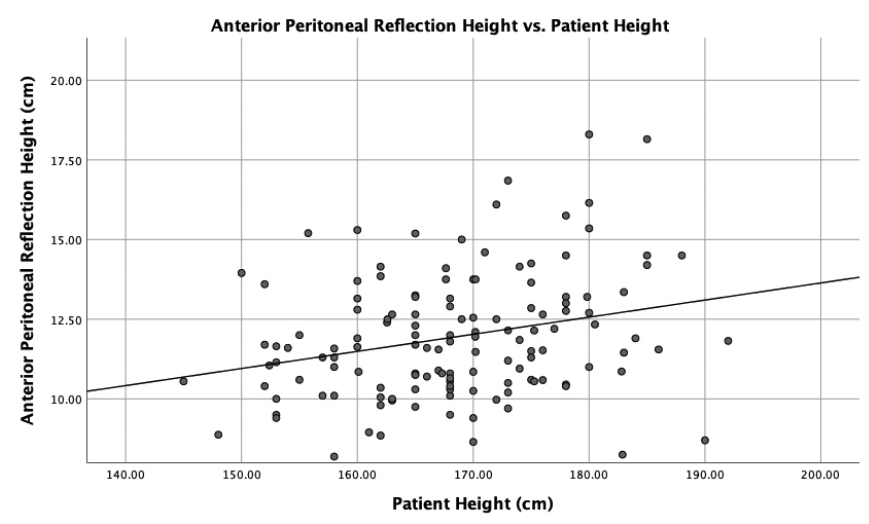

Figure 9. Anterior peritoneal reflection correlation with height 
(ICC) were calculated between measurement time points to confirm reproducibility of the measurements. An ICC $>0.800$ was considered strong correlation between the two measurements.

\section{Results}

Between January 2016 and November 2019, 278 patients were identified with a diagnosis of rectal cancer. Of these 278 patients, $7.2 \%(n=20)$ were excluded either because of previous pelvic surgery obscuring anatomical pelvic anatomy, or they had recurrent rectal cancer after oncologic resection. Of the remaining 258 patients, 60.1\% $(n=152)$ had MRI imaging available for imaging review. Of these 152 patients, 18 had poor quality imaging, preventing identification of the location of the APR or tumor. This left 134 patients with adequate quality preoperative staging MRI available for study.

Patients were $60.7 \% \quad(n=85)$ male with a mean age of $60.4 \pm 12.2$ years. The height and weight was $168.4 \pm 9.6$ $\mathrm{cm}$ and $77.9 \pm 30.5 \mathrm{~kg}$, while the median BMI was 25.2

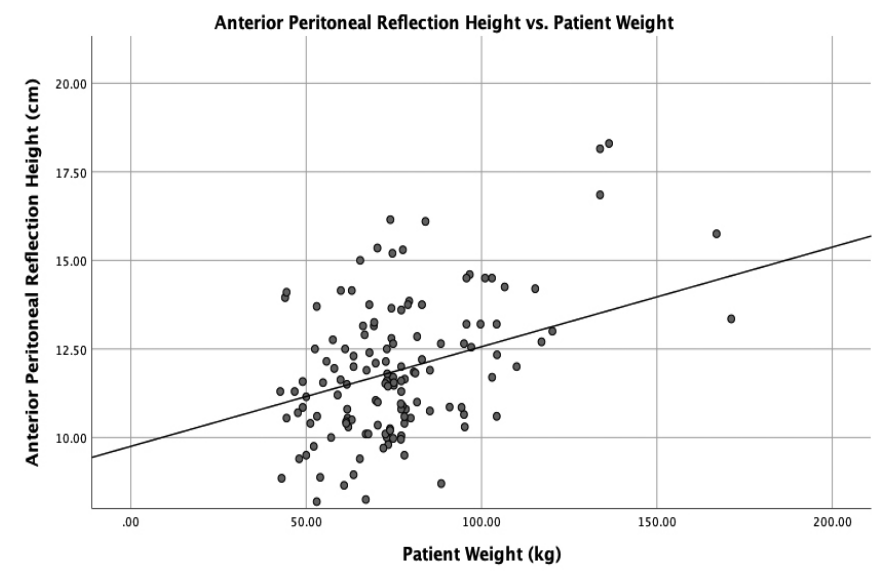

Figure 10. Anterior peritoneal reflection correlation with weight

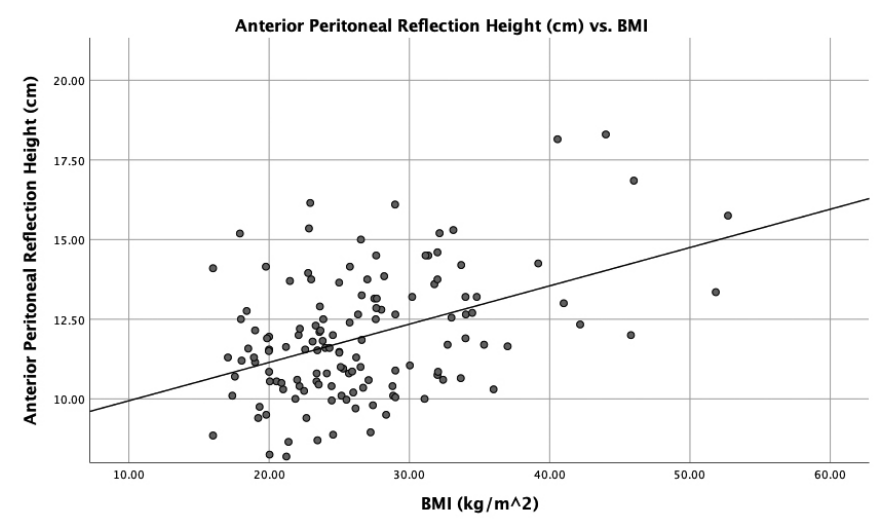

Figure 11. Anterior peritoneal reflection correlation with BMI BMI: Body mass index (interquartile range 8.0). The mean distance from the APR to anal verge was $12.0 \pm 2.0 \mathrm{~cm}$. When $75^{\text {th }}$ percentile, $90^{\text {th }}$ percentile, and $95^{\text {th }}$ percentile heights of the APR were assessed they corresponded with rectal heights of $13.2 \mathrm{~cm}$, $14.5 \mathrm{~cm}$, and $15.5 \mathrm{~cm}$, respectively The mean distance from the APR to apex of the pelvic floor was $8.5 \pm 1.7 \mathrm{~cm}$ while the average distance from the ST to apex of the pelvic floor was $10.8 \pm 1.9 \mathrm{~cm}$. The average anal canal length was $3.5 \pm 1.0 \mathrm{~cm}$. The average height of the rectum at the sacral prominence and ST was $19.3 \pm 2.4 \mathrm{~cm}$ and $14.3 \pm 2.1 \mathrm{~cm}$, respectively, from the anal verge. The average distances from the anal verge to the distal and proximal tumor edge for the cohort were $7.9 \pm 3.6 \mathrm{~cm}$ and $12.4 \pm 3.9 \mathrm{~cm}$, respectively.

\section{Male vs. Female Comparison}

The mean age was $61.1 \pm 11.6$ years for males and $59.1 \pm 13.1$ years for females $(\mathrm{p}=0.358)$. Males demonstrated a greater average patient height when compared to females $(172.5 \pm 8.1$ $\mathrm{cm}$ vs. $161.2 \pm 7.6 \mathrm{~cm}, \mathrm{p}<0.001)$. Males also demonstrated a greater average weight $(84.5 \pm 34.5 \mathrm{~kg}$ vs. $66.3 \pm 16.7 \mathrm{~kg}$, $\mathrm{p}<0.001)$. The BMI was also statistically higher in the male cohort with a male median BMI of 26.0 (IQR: 8.15 ) and female median BMI of 23.9 (IQR: 8.50) ( $\mathrm{p}=0.031)$.

The average height of the APR differed between men $(12.3 \pm 2.1 \mathrm{~cm})$ and women $(11.3 \pm 1.5 \mathrm{~cm})(\mathrm{p}=0.003)$. The mean APR to pelvic floor distance was $8.5 \pm 1.7 \mathrm{~cm}$ in the male cohort which was similar to the mean value of $8.6 \pm 2.2$ $\mathrm{cm}$ in the female cohort $(\mathrm{p}=0.703)$. When the mean APR to ST distance was compared between men and women there was again no difference at $10.8 \pm 1.9 \mathrm{~cm}$ in men and $10.8 \pm 2.0$ $\mathrm{cm}$ in women $(\mathrm{p}=0.848)$. There was a significant gender difference in mean anal canal length, which was $3.8 \pm 0.8 \mathrm{~cm}$ in men and $3.0 \pm 1.0 \mathrm{~cm}$ in women $(\mathrm{p}<0.001)$. The average height of the rectum at the sacral prominence from the anal verge was $19.3 \pm 2.4 \mathrm{~cm}$ in men and $19.5 \pm 2.3 \mathrm{~cm}$ in women $(p=0.516)$. The average height of the rectum at the ST from

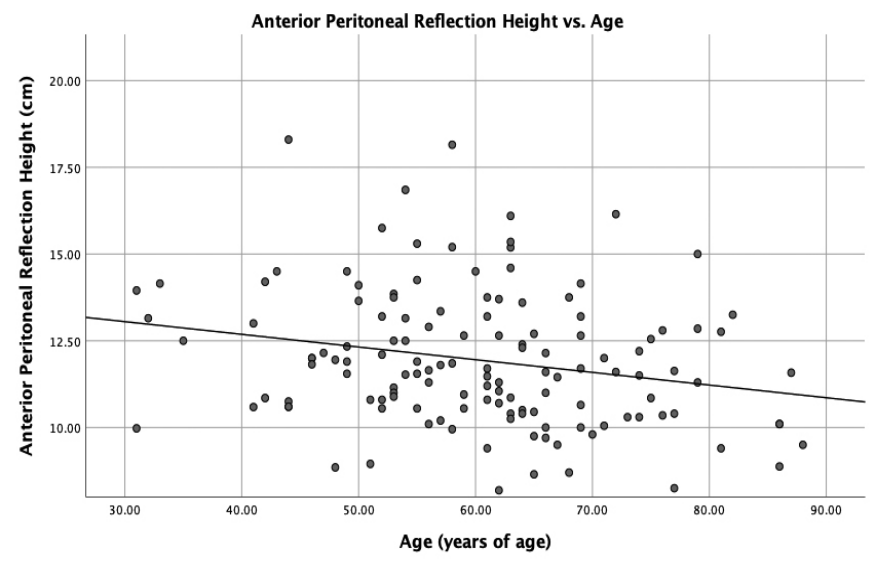

Figure 12. Anterior peritoneal reflection correlation with age 
the anal verge was $14.7 \pm 2.1 \mathrm{~cm}$ and $13.8 \pm 2.0 \mathrm{~cm}$ in men and women, respectively $(\mathrm{p}=0.019)$. In the male cohort the height of the prostate and seminal vesicles were $5.1 \pm 1.1 \mathrm{~cm}$ and $7.8 \pm 1.2 \mathrm{~cm}$, respectively (Table 1 ).

\section{Correlative Factors for Extraluminal Landmarks}

When the height of the APR was correlated with height, weight, BMI, and age, the Spearman's correlation coefficients were $0.255(\mathrm{p}=0.003, \mathrm{n}=134), 0.377(\mathrm{p}<0.001, \mathrm{n}=134)$, $0.338(\mathrm{p}<0.001, \mathrm{n}=134)$ and $-0.238 \quad(\mathrm{p}=0.006, \mathrm{n}=134)$ (Figures 9, 10, 11, 12). When the height of the rectum at the sacral promontory was correlated with height, weight, BMI, and age, the Spearman's correlation coefficients were $0.194(\mathrm{p}=0.030, \mathrm{n}=126)$ for height, $0.259(\mathrm{p}=0.003, \mathrm{n}=126)$ for weight, $0.176(\mathrm{p}=0.048, \mathrm{n}=126)$ for $\mathrm{BMI}$, and -0.186 $(\mathrm{p}=0.037, \mathrm{n}=126)$ for age. When the height of the rectum at the ST was correlated with height, weight, BMI, and age, the Spearman's correlation coefficients were 0.285 ( $<<0.001$, $\mathrm{n}=134)$ for height, $0.365(\mathrm{p}<0.001, \mathrm{n}=134)$ for weight, 0.365 $(\mathrm{p}<0.001, \mathrm{n}=134)$ for BMI, and $-0.204(\mathrm{p}=0.018, \mathrm{n}=134)$ for age. When anal canal was correlated with height, weight, BMI, and age, the Spearman's correlation coefficients were $0.400(\mathrm{p}<0.001, \mathrm{n}=134)$ for height, $0.452(\mathrm{p}<0.001, \mathrm{n}=134)$ for weight, $0.407(\mathrm{p}<0.001, \mathrm{n}=134)$ for $\mathrm{BMI}$, and -0.033 $(\mathrm{p}=0.708, \mathrm{n}=134)$ for age. When the distance between the pelvic floor and the peritoneal reflection was correlated with height, weight, BMI, and age, the Spearman's correlation coefficients were $0.019(\mathrm{p}=0.824, \mathrm{n}=134)$ for height, 0.176 （ $\mathrm{p}=0.042, \mathrm{n}=134)$ for weight, $0.208(\mathrm{p}=0.016, \mathrm{n}=134)$ for BMI, and $-0.185(\mathrm{p}=0.032, \mathrm{n}=134)$ for age. When the distance between the pelvic floor and the ST was correlated with height, weight, BMI, and age, the Spearman's correlation coefficients were $0.159(\mathrm{p}=0.066, \mathrm{n}=134)$ for height, 0.225 $(\mathrm{p}<0.001, \mathrm{n}=134)$ for weight, $0.232(\mathrm{p}=0.007, \mathrm{n}=134)$ for BMI, and $-0.227(\mathrm{p}=0.008, \mathrm{n}=134)$ for age.
In the male cohort, when the height of the prostate was correlated with height, weight, BMI, and age, the Spearman's correlation coefficients were $0.173(\mathrm{p}=0.119, \mathrm{n}=82)$ for height, $0.504(\mathrm{p}<0.001, \mathrm{n}=82)$ for weight, $0.520(\mathrm{p}<0.001$, $\mathrm{n}=82)$ for BMI, and $-0.091(\mathrm{p}=0.416, \mathrm{n}=82)$ for age. Lastly, in the male cohort, when the height of the seminal vesicles was correlated with height, weight, BMI, and age, the Spearman's correlation coefficients were 0.176 ( $\mathrm{p}=0.115$, $\mathrm{n}=82)$ for height, $0.515(\mathrm{p}<0.001, \mathrm{n}=82)$ for weight, 0.527 $(\mathrm{p}<0.001, \mathrm{n}=82)$ for BMI, and $-0.152(\mathrm{p}=0.171, \mathrm{n}=82)$ for age.

\section{Reliability Analysis}

All measurements between time points possessed an ICC of $>0.800$ signifying strong reproducibility and reliability (Table 2).

\section{Discussion}

This study, which sought to bestow a more comprehensive understanding how standardized distance cut-offs compare with variations in rectal length, succeeded in establishing the presence of a normally distributed APR (skewness 0.720, kurtosis 0.634) and ST height, (skewness 0.307, kurtosis -0.385). This study also demonstrated in both males and females that the men distance of the anatomical boundary of the rectum falls below the commonly used standardized distance cut-off of $15 \mathrm{~cm}$ in the study cohort. Utilizing this distance cut-off, established by the ASCRS, may predispose rectal cancer patients to receiving neoadjuvant chemoradiation when no clinical benefit may exist. MRI may be important establishing a more personalized treatment protocol for each patient based on individual anatomy rather than generalized standards.

When the total cohort was stratified by sex, women had significantly lower height for the APR and the ST. Of note,

Table 1. Male vs. female cohort

$\begin{array}{llll} & \text { Male } & \text { Female } & \text { p value } \\ \text { AV to APR } & 12.3 \pm 2.1 \mathrm{~cm} & 11.3 \pm 1.5 \mathrm{~cm} & 0.003 \\ \text { SC to APR } & 8.5 \pm 1.7 \mathrm{~cm} & 8.6 \pm 2.2 \mathrm{~cm} & 0.703 \\ \text { SC to ST } & 10.8 \pm 1.9 \mathrm{~cm} & 10.8 \pm 2.0 \mathrm{~cm} & 0.848 \\ \text { SC length } & 3.8 \pm 0.8 \mathrm{~cm} & 3.0 \pm 1.0 \mathrm{~cm} & \leq 0.001 \\ \text { AV to SP } & 19.3 \pm 2.4 \mathrm{~cm} & 19.5 \pm 2.3 \mathrm{~cm} & 0.516 \\ \text { AV to ST } & 14.7 \pm 2.1 \mathrm{~cm} & 13.8 \pm 2.0 \mathrm{~cm} & 0.019 \\ \text { AV to prostate } & 5.1 \pm 1.1 \mathrm{~cm} & & \\ \text { AV to SV } & 7.8 \pm 1.2 \mathrm{~cm} & & \\ \text { AV: Anal verge, APR: Anterior peritoneal reflection, SC: Sphincter complex, SP: Sacral prominence, ST: Sigmoid takeoff, SV: Seminal vesicles }\end{array}$


Table 2. Intraclass correlation coefficient calculated between measurement timepoints

\begin{tabular}{|c|c|c|c|}
\hline & Measurement 1 & Measurement 2 & ICC \\
\hline $\mathrm{AV}$ to ant $\mathrm{PR}$ & $11.9 \pm 1.9$ & $12.0 \pm 2.1$ & 0.920 \\
\hline SC to ant PR & $8.5 \pm 1.7$ & & 0.923 \\
\hline SC to ST & $10.8 \pm 2.0$ & $10.9 \pm 1.8$ & 0.957 \\
\hline SC length & $3.4 \pm 0.8$ & $3.5 \pm 0.8$ & 0.872 \\
\hline $\mathrm{AV}$ to SV & $7.7 \pm 1.2$ & $7.9 \pm 1.2$ & 0.901 \\
\hline AV to prostate & $5.1 \pm 1.1$ & $5.2 \pm 1.1$ & 0.920 \\
\hline
\end{tabular}

the distance from the pelvic floor to the APR and ST were located closer to the anal verge, the average distance of the peritoneal reflection and ST was similar between males and females. This in combination with the statistically significant difference in the anal canal length between males and females suggested that the rectum contained within the pelvis was not significantly longer in either gender. Rather, difference in the length of the anal canal could be responsible for the differences seen between the sex cohorts. Our study mirrored previous literature on variation in the length of the surgical anal canal between sexes. On average, the surgical anal canal is longer in males than in females. Intraoperative measurements of the posterior anal canal have estimated the surgical anal canal to be $4.4 \mathrm{~cm}$ in men compared with $4.0 \mathrm{~cm}$ in women. ${ }^{15}$ With our study demonstrating similar differences in anal canal length $(3.8 \mathrm{~cm}$ in males and 3.0 $\mathrm{cm}$ in females), there was an average difference of $0.8 \mathrm{~cm}$ between genders. With the average distance difference of 1.0 $\mathrm{cm}$ between male and female APR in our study, almost the entire difference can be accounted for by the shorter anal canal and not by the more concave pelvis and thus longer intra-pelvic rectum.

Another important observation is the contradiction of the current literature surrounding rectal length variation with changes in body habitus. Our study observed no strong or even moderate correlations between the APR height, ST, or the height of the rectum at the sacral prominence and any anthropometric characteristics. This demonstrated that there is no accurate way to preoperatively predict variations in the patient's APR height with patient habitus, suggesting that MRI may allow for more accurate guidance of treatment. It also suggests that changes in body metrics or habitus have limited effect on the distance to the peritoneal reflection, contradicting previous literature. ${ }^{7}$ It may, however, make obtaining these measurements in the clinical setting more difficult, as patients with greater BMI values are difficult to examine accurately with ERUS and with physical examination.

\section{Study Limitations}

Our study suffered from several limitations. Often the imaging utilized for assessment of the APR height was from an outside hospital MRI. In previous studies, outside hospital MRI imaging protocols vary drastically between institutions, with community imaging centers especially having wide variance in imaging and reporting standards. It is very difficult to obtain the resolution required to identify the peritoneal reflection on imaging qualities less than 1.5 Tesla or without use of surface coils. With inadequate protocols, accuracy of disease staging and involvement of extra-luminal structures can be greatly impacted. ${ }^{16}$ Universal standardization of rectal cancer MRI protocols and MRI reporting would greatly benefit the surgical community by facilitating a more effective exchange of knowledge between specialties. ${ }^{17,18}$ Another limitation of our study included difficulty defining the true anal verge on MRI. Even amongs radiologic societies, identification of the anal verge on MRI is a controversial topic. ${ }^{10}$ Our study utilized guidance provided by the radiologic literature to guide our assessment of the proximal and distal landmarks of our study. ${ }^{10,19}$ Previously there have been many tools utilized for measuring distance of a lesion/structure from the anal verge. These included multiple straight lines, a single straight line, and a singular curvilinear line on mid-sagittal MRI. Between the different measurement tools there is no clear consensus as to the superior tool. ${ }^{18,20,21,22,23,24}$ Our study utilized a single curvilinear line which demonstrated acceptable accuracy but 
is more difficult to recreate between observers. ${ }^{10}$ However, with the recreation of these measurements there was strong agreement between observers with all ICC $>0.870$. When assessing for the average heights, care must be taken to standardize the distal and proximal measurement endpoints. Another weakness of our study was that the prognostic implication of utilizing the APR to guide neoadjuvant chemoradiation therapy was not assessed by this study. Our study simply compared the location of the APR and ST on pelvic MRI to previously established standardized distance cut-offs.

\section{Conclusion}

While endoscopy is an important tool in the diagnosis and preoperative planning for rectal cancer resection, variance in the peritoneal reflection height between patients suggest that endoscopic measurement alone or standardized rectal length cut-offs may provide misleading or inadequate information. In addition, when the height of the peritoneal reflection in males and females was assessed, it was found that the variation in height between genders was almost entirely made up by the difference in the anal canal length. This suggests that the intrapelvic rectum is nearly the same in males and females. MRI and endoscopy, when used in conjunction have the capability to contribute complimentary data and evaluate patent specific anatomy to facilitate a more efficacious treatment plan and the avoidance of inappropriate neoadjuvant chemoradiation administration.

Consent for publication: Consent for publication was granted by our institutional IRB (HS-17-00058)

Presented at: The American Society of Colorectal Surgeons annual meeting 2021 (virtual)

\section{Ethics}

Ethics Committee Approval: IRB approval was granted for the completion of this study with the ID number HS-1700058

Peer-review: Internally peer reviewed.

\section{Authorship Contributions}

Concept: J.W., G.T., N.S., J.M., M.P.D., K.G.C., S.W.L.

Conflict of Interest: No conflict of interest was declared by the authors.

Financial Disclosure: The authors declared that this study received no financial support.

\section{References}

1. Kapiteijn E, Marijnen CAM, Nagtegaal ID, Putter H, Steup WH, Wiggers T, Rutten HJ, Pahlman L, Glimelius B, van Krieken JH, Leer JW, van de Velde CJ, Dutch Colorectal Cancer Group. Preoperative Radiotherapy Combined with Total Mesorectal Excision for Resectable Rectal Cancer. N Engl J Med 2001;345:638-646.

2. Marinello FG, Frasson M, Baguena G, Flor-Lorenta B, Cervantes A, Roselló S, Espí A, García-Granero E. Selective approach for upper rectal cancer treatment: Total mesorectal excision and preoperative chemoradiation are seldom necessary. Dis Colon Rectum 2015;58:556-565.

3. Herman JM, Narang AK, Griffith KA, Zalupski MM, Reese JB, Gearhart SL, Azad NS, Chan J, Olsen L, Efron JH, Lawrence TS, Ben-Josef E. The quality-of-life effects of neoadjuvant chemoradiation in locally advanced rectal cancer. Int J Radiat Oncol Biol Phys 2013;85:e15.

4. Topor B, Acland R, Kolodko V, Galandiuk S. Mesorectal lymph nodes: Their location and distribution within the mesorectum. Dis Colon Rectum 2003:46:779-785

5. Sauer R, Becker H, Hohenberger W, Rödel C, Wittekind C, Fietkau R, Martus P, Tschmelitsch J, Hger E, Hess CF, Karstens J-H, Liersch T, Schmidberger H, Raab R, German Rectal Cancer Study Group. Preoperative versus Postoperative Chemoradiotherapy for Rectal Cancer. N Engl J Med 351:1731-1740

6. You YN, Hardiman KM, Bafford A, Poylin V, Francone TD, Davis K, Paquette IM, Steele SR, Feingold DL. The american society of colon and rectal surgeons clinical practice guidelines for the management of rectal cancer. Dis Colon Rectum 2020;63:1191-1222.

7. Scott N, Jackson P, Al-Jaberi T, Dixon MF, Quirke P, Finan PJ. Total mesorectal excision and local recurrence: A study of tumour spread in the mesorectum distal to rectal cancer. Br J Surg 82:1031-1033.

8. McMullen TPW, Easson AM, Cohen Z, Swallow CJ. The investigation of primary rectal cancer by surgeons: Current pattern of practice. Can J Surg 2005;48:19-26.

9. Cuschieri S. The STROBE guidelines. Saudi J Anaesth 2019;13:S31-S34.

10. Han YE, Park BJ, Sung DJ, Kim MJ, Han NY, Sim KC, Cho SB, Kim J, Kim $\mathrm{S}-\mathrm{H}, \mathrm{An} \mathrm{H}$. How to accurately measure the distance from the anal verge to rectal cancer on MRI: a prospective study using anal verge markers. Abdom Radiol 2021;46:449-458.

11. D'Souza N, de Neree tot Babberich MPM, d'Hoore A, Tiret E, Xynos E, Beets-Tan RGH, Nagtegaal ID, Blomqvist L, Holm T, Glimelius B, Lacy A, Cervantes A, Glynne-Jones R, West NP, Pere RO, Quadros C, Lee KY, Madiba TE, Wexner SD, Garcia-Aguilar J, Sahani D, Moran B, Tekkis P, Rutten HJ, Tanis PJ, Wiggers T, Brown G. Definition of the rectum: An International, expert-based Delphi consensus. Ann Surg 2019;270:955959

12. Nivatvongs S, Stern HS, Fryd DS. The length of the anal canal. Dis Colon Rectum 1981;24:600-601

13. Suzuki C, Torkzad MR, Tanaka S, Palmer G, Lindholm J, Holm T, Blomqvist L. The importance of rectal cancer MRI protocols on interpretation accuracy. World J Surg Oncol 2008;6:89

14. Tersteeg JJC, Gobardhan PD, Crolla RMPH, Kint PAM, Niers-Stobbe I, Boonman-de Winter LJM, Schreinemakers JML. Improving the quality of mri reports of preoperative patients with rectal cancer: Effect of national guidelines and structured reporting. Am J Roentgenol 2018;210:12401244.

15. Nougaret S, Reinhold C, Mikhael HW, Rouanet P, Bibeau F, Brown G. The use of MR imaging in treatment planning for patients with rectal carcinoma: Have you checked the "DISTANCE." Radiology 2013;268:330-334. 
16. Yiqun S, Tong T, Fangqi L, Sanjun C, Chao X, Yajia G, Ye X. Recognition of anterior peritoneal reflections and their relationship with rectal tumors using rectal magnetic resonance imaging. Medicine (Baltimore) 2016;95:e2889

17. KSAR Study Group for Rectal Cancer. Essential items for structured reporting of rectal cancer MRI: 2016 consensus recommendation from the Korean society of abdominal radiology. Korean J Radiol 2017;18:132-151.

18. Han NY, Kim MJ, Park BJ, Sung DJ. Location of rectal cancer as determined using rectal magnetic resonance imaging, and its relationship with pulmonary metastasis. Turkish J Gastroenterol 2014;25:661-668.
19. Hoeffel C, Mulé S, Laurent V, Bouché O, Volet J, Soyer P. Primary rectal cancer local staging. Diagn Interv Imaging 2014;95:485-494.

20. Arya S, Das D, Engineer R, Saklani A. Imaging in rectal cancer with emphasis on local staging with MRI. Indian J Radiol Imaging 2015;25:148161.

21. Furey E, Jhaveri KS. Magnetic resonance imaging in rectal cancer. Magn Reson Imaging Clin N Am 2014;22:165-190. 